\title{
PILOT STUDI: MANAJEMEN DIRI PASIEN DIABETES MELITUS DI RUMAH SAKIT HL. MANAMBAI ABDULKADIR
}

\author{
Pilot study: Self-Management Among Diabetes Mellitus Patients at HL. Manambai \\ Abdulkadir Hospital
}

\author{
Satriya Pranata \\ Departement Keperawatan Medikal Bedah, Fakultas \\ Ilmu Keperawatan dan Kesehatan, Universitas \\ Muhammadiyah Semarang, Indonesia \\ e-mail: satriya.pranata@unimus.ac.id
}

\begin{abstract}
ABSTRAK
Latar Belakang: Populasi penderita diabetes melitus terus meningkat setiap tahunnya dan termasuk dalam kategori penyakit paling mematikan nomor tiga di Indonesia. Total pasien diabetes melitus di Indonesia saat ini berjumlah 10.3 juta penderita, diprediksi pada tahun 2045, populasi tersebut akan bertambah menjadi 16.7 juta penderita. Penyebab utama penambahan populasi penderita diabetes melitus ini dapat terjadi dikarenakan oleh kesadaran masyarakat akan pentingnya management diri masih sangat kurang. Belum pernah dilakukan penelitian mengenai gambaran manajemen diri penderita diabetes melitus di rumah sakit HL. Manambai Abdulkadir. Tujuan Pilot Studi: tujuan utama dalam pilot studi ini adalah ingin memahami tentang manajeme diri penderita diabetes melitus di rumah sakit HL. Manambai Abdulkadir. Metedologi: Patisipan dalam pilot studi ini adalah penderita diabetes melitus tipe 2 di rumah sakit HL. Manambai Abdulkadir. Desain yang digunakan adalah cross sectional dengan bantuan instrument diabetes self-management self-efficacy, diabetes self-management questionnaire, diabetes selfmanagement knowledge dan diabetes distress scale. Hasil: 60\% manajemen diri penderita diabetes melitus di rumah sakit HL. Manambai Abdulkadir tergolong rendah. Skala distress, pengetahun dan efikasi diri pasien berhubungan erat dengan manajemen diri penderita diabetes melitus dengan $\mathrm{P}$ Value $<0.05$. Kesimpulan: butuh dilakukan penelitian lanjutan dengan intervensi tambahan untuk mengatasi rendahnya manajemen diri penderita diabetes melitus di Rumah sakit HL. Manambai Abdulkadir.
\end{abstract}

Kata kunci: diabetes melitus, manajemen diri, efikasi diri, pengetahuan, skala distress

\section{ABSTRACT}

Background: The population of people with diabetes mellitus is increasing every year, furthermore included into number three of deadliest disease in Indonesia. The total number of patients with diabetes mellitus currently are 10.3 million, predicted in 2045, the population will increase to 16.7 million. The main cause population of people with diabetes mellitus are increasing due to public awareness regarding self-management is still less. No researcher has been conducted research about diabetes self-management in HL. Manambai Abdulkadir hospitals. Objectives of the Pilot Study: the main objective in this pilot study was to understand the selfmanagement of people with diabetes mellitus in HL Manambai Abdulkadir hospitals. Methodology: The participants in this pilot study were people diabetes mellitus type 2 in HL Manambai Abdulkadir hospitals using cross sectional design by diabetes self-management, self-efficacy, diabetes self-management knowledge and diabetes distress scale questionnaire. Results: 60\% of patients in HL Manambai Abdulkadir hospitals had lack of self-management. The result from measuring of distress scale, knowledge and self-efficacy of patients are related to self-management of patients with diabetes mellitus with $P$ Value <0.05. Conclusion: further research is needed with additional interventions to overcome the lack of self-management to people who suffer diabetes mellitus in HL Manambai Abdulkadir Hospital.

Key Words: diabetes mellitus; self-management; self-efficacy; Knowledge; distress scale 


\section{PENDAHULUAN}

Populasi penderita diabetes mellitus (DM) terus meningkat setiap tahunnya. Total pasien Diabetes Mellitus (DM) di seluruh dunia adalah 425 juta orang, yang meningkat $48 \%$ daripada setiap tahun sebelumnya. Prediksi pada 2045, populasi akan meningkat hingga 629 juta. Peningkatan ini juga terjadi di Indonesia. Pasien DM di Indonesia pada tahun 2017 adalah 159 juta, jumlah ini meningkat $15 \%$ dari tahun sebelumnya, dan diperkirakan pada tahun 2045, jumlahnya akan bertambah menjadi 183 juta, (IDF, 2017).

Saat ini, Indonesia menduduki ranking ke enam Negara dengan penduduk dewasa penderita diabetes melitus, melanin itu diabetes melitus juga masuk dalam ranking ke tiga sebagai penyakit paling mematikan, (IDF, 2017; WHO, 2016). Alaskan Utama kejadian ini dapat terjadi dikarenakan oleh berbagai factor seperti kesadaran diri dan pengetahuan penderita diabetes yang masih kurang, asked ke fasilitas kesehatan yang masih sulit, khawatir bill kondisi kesehatannya akan diketahui lebih buruk bill melakukan pengecekan, dan komplikasi yang sering terjadi, (Phasar, 2018; Pranata, 2017a, 2017b; Pranata, 2016; Rufaidah, 2018).

Upaya untuk mengatasi kondisi tersebut khususnya kesadaran diri yang kurang, dibutuhkan promosi kesehatan yang baik agar penderita diabetes melitus dapat lebih sadar kesehatan dan aktif dalam melakukan perawatan diri, (Sassen, 2018). Aktif dalam perawatan diri inilah yang dinamakan dengan management diri penderita diabetes melitus, (Day and Schleicher, 2009; Koetsenruijter et al., 2014; Mertig, 2007; Udlis, 2011).

Manajemen diri adalah kapasitas pasien untuk menangani masalah kesehatan, gejala dan konsekuensi fisik dan psikososial dari masalah kesehatannya, dan untuk membuat perubahan gaya hidup yang menetap. Manajemen diri yang efektif mencakup kemampuan untuk memantau kondisi seseorang dan untuk mencapai respons kognitif, perilaku dan emosional yang diperlukan untuk mempertahankan kualitas hidup yang memuaskan, (Ncama, 2011). Manajemen diri adalah proses yang dinamis, interaktif, dan sehari-hari di mana individu terlibat untuk mengelola penyakit kronis, (Lorig, Holman, \& Med, 2003). Manajemen diri mengacu pada "kemampuan individu, dalam hubungannya dengan keluarga, komunitas, dan profesional kesehatan, untuk mengelola gejala, perawatan, perubahan gaya hidup, dan konsekuensi psikososial, budaya, dan spiritual dari kondisi kesehatan, (Richard, 2011). Manajemen diri yang optimal mencakup kemampuan untuk memantau penyakit dan mengembangkan serta menggunakan strategi kognitif, perilaku, dan emosional untuk mempertahankan kualitas hidup yang memuaskan, (Creer \& Holroyd, 2006; Ncama, 2011; Sassen, 2018; Wu, Liang, Wang, Chen, \& Jian, 2011). Meskipun manajemen diri sangat populer dalam sistem perawatan kesehatan, konsep tentang manajemen diri pada diabetes mellitus kadang masih split dipahami. Kesalahan memaknai manajemen diri pada penderita diabetes mellitus dapat menyebabkan kebingungan dan kerancuan intervensi keperawatan pada pasien. Selama ini, belum pernah dilakukan penelitian mengenai manajemen diri penderita diabetes melitus di rumah sakit HL. Manambai Abdulkadir. Melihat pentingnya mengetahui tentang perawatan diri penderita diabetes melitus di rumah sakit HL Manambai Abdulkadir serta belum adanya penelitian serupa, maka pilot studi ini perlu dilakukan. Tujuan dilakukannya pilot studi ini adalah untuk mengetahui dan memahami tentang manajemen diri penderita diabetes melitus di Rumah Sakit HL. Manambai Abdulkadir.

\section{METODE}

Pilot studi yang dilakukan menggunakan cross sectional design. Pilot studi ini dilakukan sejak 15-22 Januari 2019 di Rumah Sakit HL. Manambai Abdulkadir, Kota Sumbawa Besar, Provinsi Nusa Tenggara Barat. Jumlah responden dalam pilot studi ini adalah 10 responden. Dalam pilot studi ini responden yang ditetapkan responden yang memenuhi kriteria inklusi dan responden yang tidak terekslusi. Kriteria inklusi pada pilot studi ini adalah: pasien penderita diabetes melitus tipe 2, melakukan rawat jalan atau rawat inap di rumah sakit, bersedia dan koperatif ketika 
dilakukan pengambilan data. Kriteria ekslusi pada pilot studi ini: Pasien DM yang memiliki penyakit lain seperti jantung, atau komplikasi ulkus DM dan neuropati. Kuesioner yang digunakan adalah kuesioner karakteristik responden, kuesioner diabetes self-management, diabetes self-efficacy, diabetes self-management knowledge dan diabetes distress scale. Semua instrument dalam penelitian ini sudah pernah diuji validitas dan reliabilitasnya oleh peneliti lain di Indonesia. Bahasa yang digunakan sudah dimodifikasi dengan sederhana agar memudahkan responden dalam mengisi dan menjawab setiap item pertanyaan. Sebelum pilot studi dilaksanakan, peneliti mengajukan permohonan tertulis kepada direktur Rumah Sakit HL Manambai Abdulkadir, Kota Sumbawa Besar, Nusa Tenggara Barat. Setelah disetujui oleh rumah sakit, selanjutnya peneliti melakukan sosialisasi, menjelaskan tentang maksud, tujuan dan prosedur pilot studi kepada kepala ruang, staf perawat dan dokter penanggung jawab pasien. Peneliti memilih pasien berdasarkan kriteria yang sudah ditentukan. Setelah pasien masuk dalam kriteria inklusi, peneliti kemudian meminta kesediaan calon responden untuk berpartisipasi setelah mendapatkan penjelasan tentang maksud, tujuan, manfaat, prosedur pilot studi, serta hak dan kewajiban menjadi responden. Bagi responden yang bersedia, peneliti selanjutnya meminta calon responden menandatangani lembar inform concern kemudian mengisi setiap kuesioner dengan pendampingan agar tidak terjadi kesalahan dalam pengisian.

\section{HASIL DAN PEMBAHASAN HASIL}

Tabel 1. Karakteristik responden

\begin{tabular}{llll}
\hline \multicolumn{1}{c}{ Variabel } & N & \% & Total (\%) \\
\hline Usia & & & $10(100 \%)$ \\
$-\quad$ Usia 60-74 & 6 & $60 \%$ & \\
$\quad$ tahun & 4 & $40 \%$ & \\
$-\quad \begin{array}{l}\text { Usia 45-59 } \\
\text { tahun }\end{array}$ & & & \\
\hline Jenis Kelamin & & & $10(100 \%)$ \\
\hline
\end{tabular}

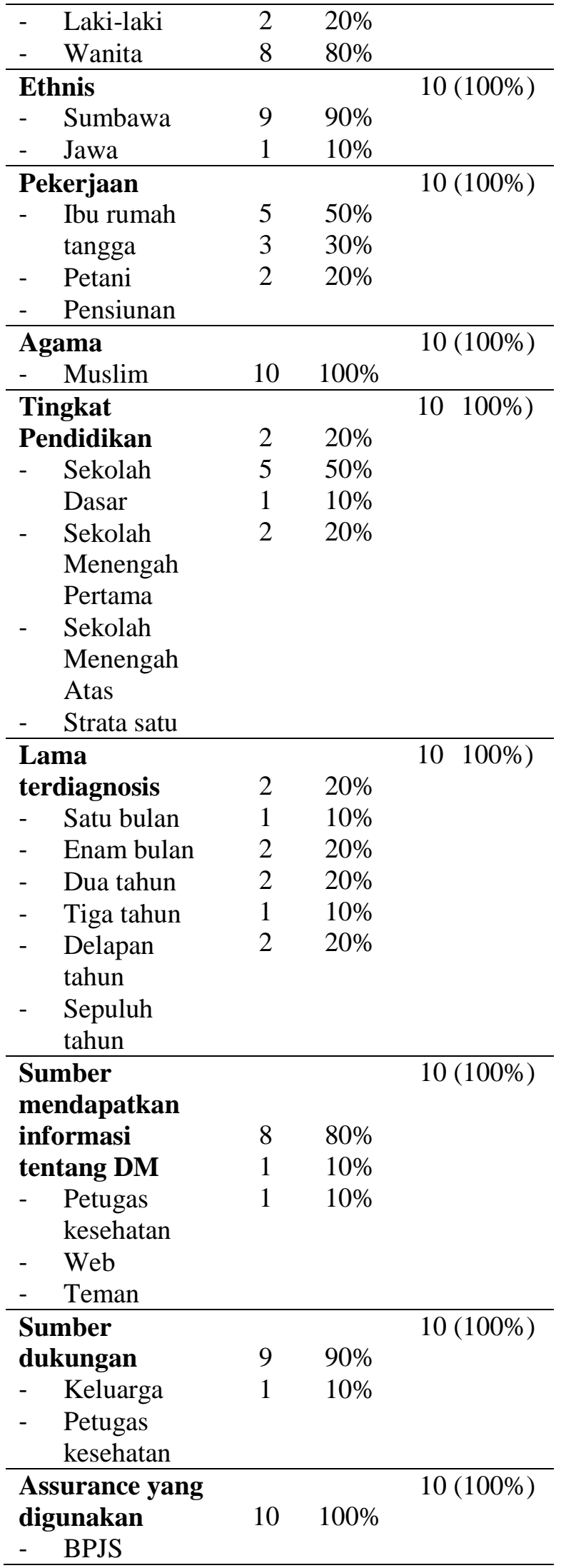


Tabel 2. Pengukuran manajemen diri, efikasi diri, diabetes distress dan pengetahuan pasien akan diabetes

\begin{tabular}{lccl}
\hline \multicolumn{1}{c}{ Variabel } & N & \% & \multicolumn{1}{c}{ Total } \\
\hline Manajemen diri & & & 10 \\
- Cukup bagus & 3 & $30 \%$ & $(100 \%)$ \\
- Sedang-sedang & 1 & $10 \%$ & \\
- Kurang & 6 & $60 \%$ & \\
\hline Efikasi diri & & & 10 \\
- Cukup bagus & 2 & $20 \%$ & $(100 \%)$ \\
- Sedang-sedang & 3 & $30 \%$ & \\
- Buruk & 5 & $50 \%$ & \\
\hline Diabetes Distress & & & 10 \\
- Regimen related & 7 & $70 \%$ & $(100 \%)$ \\
$\quad \quad$ distress and & & & \\
$\quad$ emotional & 1 & $10 \%$ & \\
$\quad$ burden & 2 & $20 \%$ & \\
- Interpersonal & & & \\
$\quad \quad$ distress & & & \\
- Physical related & & & \\
$\quad$ distress & & & \\
\hline Pengetahuan akan & & & 10 \\
diabetes & 3 & $30 \%$ & $(100 \%)$ \\
- Bagus & 2 & $20 \%$ & \\
- Sedang & 3 & $30 \%$ & \\
- Rendah & 2 & $20 \%$ & \\
- Sangat rendah & & & \\
\hline
\end{tabular}

Tabel 3. Hubungan Antara skala distress, pengetahuan dan efikasi diri terhadap manajemen diri

\begin{tabular}{lccc}
\hline & $\begin{array}{c}\text { Skala } \\
\text { Distres } \\
\mathrm{s}\end{array}$ & $\begin{array}{c}\text { Pengetahua } \\
\mathrm{n}\end{array}$ & $\begin{array}{c}\text { Efikas } \\
\text { i diri }\end{array}$ \\
\hline $\begin{array}{l}\text { Manajeme } \\
\text { n diri }\end{array}$ & 0.08 & 0.08 & 0.018 \\
$\begin{array}{l}\text { Sig. (2- } \\
\text { tailed) }\end{array}$ & 10 & 10 & 10 \\
$\mathrm{~N}$ & & & \\
\hline
\end{tabular}

Perawatan diri pasien mayoritas buruk $60 \%$ padahal $70 \%$ pasien sudah terdiagnosa diabetes 2-10 tahun. Pasien mengaku masih sering mengkonsumsi banyak makanan yang mengandung gukosa tinggi dan mengaku belum mampu mengatur makanannya.
Beberapa pasien sering menggunakan obat traditional atau herbal untuk membuat gukosa darahnya stabil. Pasien memiliki ekspektasi dan harapan bahwa penyakit diabetes dapat diatasi seperti penyakit lainnya, bila sudah minim obat penyakitnya akan segera sembuh. Data ini sejalan dengan penelitian yang pernah dilakukan oleh Atak tahun 2008 yang menyatakan bahwa terdapat kesalahan persepsi dan kesenjangan terkait pemahaman pasien diabetes melitus terhadap penyakitnya. Meski pengobatan traditional tidak dapat dijauhkan dari kehidupan masyarakat saat ini, namun upaya pemberian informasi dalam bentuk pendidikan kesehatan yang inovatif dan pendekatan yang tepat oleh petugas kesehatan ke pasien akan mampu membuat pasien ikut aktif melakukan perawatan diri dengan baik melalui olahraga teratur dan pengaturan diet selama berada di rumah, (Atak, 2008; Sassen, 2018).

Pasien beranggapan bahwa pengobatan merupakan cara terbaik untuk sembuh, kondisi ini dibuktikan dengan $100 \%$ pasien mengaku selalu rutin dan tidak pernah absen ketika diminta dokter untuk kontrol di puskesmas atau rumah sakit untuk diberikan obat pengatur gua darah. Kenyataan ini membuktikan bahwa pasien lebih cenderung pasif mengikuti semua saran tenaga kesehatan untuk berobat bukan berperilaku aktif dalam mengatur gula darahnya melalui makanan dan olahraga, (Mertig, 2007; Ploughman, 2012; Wu, 2011). Jalan terbaik untuk mempertahankan gula darah tetap dalam batas normal adalah dengan pengaturan diet dan olahraga, (Sassen, 2018). Selama pasien belum diwajibkan untuk mengkonsumsi obat oral ataupun penggunaan insulin secara rutin maka pengaturan makan dan olahraga tetap menjadi pilihan terbaik, (Pranata, 2017).

Kenyataan dari hasil pengumpulan data dan wawancara dengan pasien, mereka melakukan manipulasi diet sebelum melakukan kontrol di rumah sakit. Beberapa hari sebelum kontrol, pasien mengatur makannya dan melakukan olahraga agar hasil gula darahnya cenderung baik ketika diperiksa di rumah sakit. Dengan kenyataan ini dapat ditarik kesimpuan bahwa pemeriksaan gula darah puasa atau gula darah 
sewaktu di laboratorium selama ini bukan pemeriksaan terbaik untuk pasien rawat jalan di rumah sakit HL Manambai Abdukadir. Akan lebih baik bila dilakukan pemeriksaan HbA1c secara berkala 3 atau 6 bulan sekali. Selain Karena mampu Merekam management diri pasien selama 3 bukan kebelakang, HbA1c juga dapat dijadikan prediktor apakah pasien memiliki peluang mengalami komplikasi lain atau tidak dimasa mendatang, (American Diabetes Association, 2017).

$50 \%$ pasien dalam pilot studi ini tidak memiiki keyakinan yang baik untuk mampu melakukan perawatan dirinya. Kondisi ini sejalan dengan pengetahuan pasien yang masih tergolong rendah. Pasien yang memiiki pengetahuan yang baik tentang diabetes hanya 30\% kemudian sisanya $70 \%$ berada pada rentang sedangsedang saja, buruk, hingga sangat buruk. Efikasi diri memiliki kaitan rest dengan pengetahuan pasien, (Sassen, 2018; Wu \& Kao, 2013). Kegiatan rutin melalui konsultasi gizi sudah sering dilakukan oeh ahi gizi di rumah sakit. Namun dengan data ini terlihat bahwa perlu ada upaya tambahan untuk mengatasi kesenjangan tersebut. Rumah sakit perlu memikirkan tentang pembuatan komunitas diabetes di rumah sakit, diakukannya seminar awam, diskusi keompok melalui support group antar pasien DM. Melalui pengaktifan kelompok diabetes, perawat, ahli gizi dan dokter dapat bersinergi dan bekerja sama untuk melakukan pengelolaan tersebut terutama pemberian edukasi secara rutin mengenai diabetes melitus dan penaganannya. Melalui seminar awam yang rutin diaksanakan, pasien dapat membawa anggota keuarganya sebagai kelompok yang beresiko tinggi, harapannya, penambahan jumlah penderita DM dapat ditekan semininal mungkin, serta keluarga memiliki pengetahuan yang cukup untuk ikut aktif membantu anggota keuarga lainnya dalam management diri.

$70 \%$ pasien diabetes melitus mengalami distress karena proses pengobatan dan treatment rutin yang harus dijalani (diet, obat, olahraga), dan $20 \%$ pasien mengalami distress karena kondisi fisik yang melemah dan $10 \%$ pasien mengalami masalah interpersonal. Ada beberapa hal yang menarik dari pasien di
Rumah Sakit HL. Manambai Abdulkadir, pasien yang memiliki kedekatan kuat dengan keagamaan cenderung mengalami penurunan pada beban mental dan distress pengobatan. Pasien selalu berbagi keluhannya melalui tahajud dan sholat minimal 5 kali sehari sehingga pasien merasa ebih kuat, tenang dan memiliki keyakinan bahwa ini hanya cobaan yang bersifat sementara dan tetap akan berakhir. Hasil ini sejalan dengan penelitian yang dilakukan oleh Suciani pada tahun 2018 yang menyatakan bahwa ada hubungan antara spiritualitas dengan tingkat stres pada penderita diabetes melitus, (Suciani \& Nuraini, 2018). Selain itu dikatakan bahwa, pasien dengan keihlasan yang tinggi mengaku ada kekuatan besar disampingnya yang membuat pasien selalu kuat menghadapi berbagai kondisi kesehatan yang dialaminya, (Yan, Marisdayana, \& Irma, 2017).

\section{KESIMPULAN}

Perawatan diri pasien mayoritas buruk, sebagian pasien tidak memiiki keyakinan untuk mampu melakukan perawatan diri dengan baik, pengetahuan pasien akan manajemen diri mayoritas berada pada rentang sedang-sedang saja, buruk, hingga sangat buruk. Sebagian besar pasien mengalami distress Karena peroses pengobatan dan treatment rutin yang harus dijalani dan beban mental karena sakit diabetes kemudian sebagiannya mengalami distress karena kondisi fisik yang melemah dan masalah interpersonal. Ada hubungan antara pengetahuan, efikasi diri dan skala distress terhadap manajemen diri pasien diabetes melitus.

\section{DAFTAR PUSTAKA}

American Diabetes Association. (2017). Standards of Medical Care in Diabetes. Diabetes care in the hospital. Diabetes Care 2017;40(Suppl. 1):S120-S127.

Atak, N. (2008). The effect of education on knowledge, self-management behaviours and self-efficacy of patients with type 2 diabetes. Australian Journal of Advance Nursing, 66-74. Retrieved from http://ajan.com.au/vol26/26-2_atak.pdf. 
Creer, T. L., \& Holroyd, K. A. (2006). Selfmanagement of chronic conditions: the legacy of Sir William Osler. Chronic Illness, 2(1), 7-14. https://doi.org/10.1179/174592006X9382 4

Day, D and Schleicher, D. (2009). SelfMonitoring, The Encyclopedia of Positive Psychology, 19, 886-888.

IDF. (2017). International Diabetes Federation Diabetes Atlas (8th ed) Brussels, Belgium: Retrieved from www.diabetesatlas.org.

Koetsenruijter, J., Lieshout, J. Van, Vassilev, I., Portillo, M. C., Serrano, M., Knutsen, I., ... Wensing, M. (2014). Social support systems as determinants of selfmanagement and quality of life of people with diabetes across Europe : study protocol for an observational study. Health and Quality of Life Outcomes, 12(1), 1-9. https://doi.org/10.1186/14777525-12-29

Lorig, K. R., Holman, H. R., \& Med, A. B. (2003). Self-Management Education : History, Definition, Outcomes , and Mechanisms.

Mertig, R. (2007a). The Nurse's Guide to Teaching Diabetes Self-Management. United Stated of America: Springer Publishing Company.

Mertig, R. (2007b). The nurse guide to teaching diabetes self-management. New York: Springer Publishing Company.

Ncama, B. P. (2011). Self, self-care and selfmanagement concepts : implications for self-management education, (August 2016).

Phasar, Imran. Armiaty Yuni, Pranata, S. (2018). Pengaruh pencucian luka antara larutan nacl $0.9 \%$ dengan kombinasi larutan nacl $0.9 \%$ dan rebusan daun sirih merah $40 \%$ terhadap proses penyembuhan luka kaki diabetes. Jjurnal luka indonesia. 2018, 4(2): 57-65
Conflict.

Ploughman M, Austin MW, Murdoch M, Kearney A, Godwin M, S. M. (2012). The path to selfmanagement: a qualitative study involving older people with multiple sclerosis. Physiotherapy Canada. 64(1):6-17. DOI: 10.3138/ptc.2010-42 [PubMed: 23277680].

Pranata, S. (2017a). Marawat Penderita Diabetes Melitus. Yogyakarta: Pustaka Panasea.

Pranata, S. (2017b). Perbedaan Tingkat Kecemasan Pada Pasien Diabetes Melitus Dengan Neuropati Perifer Yang Diberikan Intervensi TENS Dan Intervensi Nafas Dalam Saat Dilakukan Perawatan Ulkus Kaki Diabetik Di RSUD Kota Yogyakarta. Nurscope. Jurnal Keperawatan dan Pemikiran Il.

Pranata, S., Hs, K. H. N., \& Sujianto, U. (2016). The Effect Of Transcutaneous Electrical Nerve Stimulation ( Tens ) Towards Pain Level Of Patients With Diabetes Mellitus ( Dm ) With Peripheral Neuropathy In Diabetic Foot Ulcer Treatment In Yogyakarta General Hospital Indonesia Abstract :, 5(5), 7680. https://doi.org/10.9790/19590505037680

Richard AA, S. K. (2011). Delineation of selfcare and associated concepts. Journal of Nursing Scholarship. 43:255-264.

Rufaidah, Pranata, S. (2018). Effect of Transcutaneous Eelectrical Nerve Sstimulation ( TENS ) On the Wound Healing Process in Patients with Diabetes Mellitus Carried Diabetic Foot Ulcer Treatment at Roemani Muhammadiyah Hospital, Semarang Abstract :, 7(4), 4145. https://doi.org/10.9790/19590704064145

Sassen, B. (2018). Nursing: Health Education and Improving Patient Self-Management. https://doi.org/10.1007/978-3-319-517698 
Suciani, T., \& Nuraini, T. (2018). Kemampuan Spiritualitas Dan Tingkat Stres Pasien Diabetes Mellitus Di Rumah Perawatan: Studi Pendahuluan. Jurnal Keperawatan Indonesia, 20(2), 102. https://doi.org/10.7454/jki.v20i2.360

Udlis, K. A. (2011). Self-management in chronic illness : concept and dimensional analysis. https://doi.org/10.1111/j.17529824.2011.01085.x

WHO. (2016). Diabetes. http://www.who.int/diabetes/en/. (Accessed, 2018 october 14).

Wu FL, Juang JH, Y. M. (2011). The dilemma of diabetic patients living with hypoglycaemia. Journal of Clinical Nursing. 20(15-16):2277-2285. DOI: 10.1111/j.1365-2702.2011.03725.x [PubMed: 21627701].

Wu, S. V., Liang, S., Lee, M., Yu, N., \& Kao, M. (2013). The efficacy of a selfmanagement programme for people with diabetes, after a special training programme for healthcare workers in Taiwan : a quasi-experimental design, 2515-2524.

https://doi.org/10.1111/jocn.12440

Wu, S. V., Liang, S., Wang, T., Chen, M., \& Jian, Y. (2011). A self-management intervention to improve quality of life and psychosocial impact for people with type 2 diabetes, 2655-2665.

https://doi.org/10.1111/j.13652702.2010.03694.x

Yan, L. S., Marisdayana, R., \& Irma, R. (2017). Hubungan Penerimaan Diri Dan Tingkat Stres Pada Penderita Diabetes Mellitus. Jurnal Endurance, 2(3), 312. https://doi.org/10.22216/jen.v2i3.2234 